Original Article

\title{
WORK SAM PLING : A QUANTITATIVE ANALYSIS OF NURSING ACTIVITY IN A MEDICAL WARD
}

\author{
A. Tamilselvi ${ }^{1} \&$ Rajee Regunath ${ }^{2}$ \\ ${ }^{1}$ HOD, M edical Surgical Nursing, P.S.G College of Nursing, Coimbatore- 641004, TN, \\ ${ }^{2}$ Principal, Amla College of Nursing, Amla Nagar, Trichur, Kerala- 680555 \\ Correspondence: \\ Tamilselvi A., \\ HOD, Medical Surgical Nursing, P.S.G. College of Nursing, Coimbatore - 641 004, T.N.
}

Mobile : +919894594932

\begin{abstract}
:
Nurses perform direct nursing care activities as well as participate in other "indirect" nursing care activities such as ward administration, management and continued professional development activities which form part of the nursing work load in medical ward. Thus it is necessary to understand the proportion of nursing work load assigned to other activities and trends of variation in nursing activities throughout the day in order to estimate the actual staffing requirements. A work sampling method was used and a snapshot of nursing activity was recorded at 10 minute intervals from $7.00 \mathrm{am}$ to $7.00 \mathrm{pm}$ for a week. The results revealed that a total of 1335 activities were observed and recorded over a week time and categorized as follows: Basic nursing care $(6.2 \%)$, complex nursing care (66.8\%), administration (4.1\%), clerical (9.9\%), housekeeping (1.7\%), maintenance $(2.4 \%)$ and non productive activities $(8.7 \%)$. The proportion of complexnursing care activities mainly concentrated in morning shifts and to a lesser extent $n$ the afternoon shifts. It was concluded that more than half of the nursing activities performed by staff nurses were complex nursing activities. Also nurses perform other activities such as clerical, administration and non productive activities and these activities must be considered for estimating staffing requirements.
\end{abstract}

Keywords : Activity analysis, work sampling, nursing activities

\section{Introduction:}

Cost effective nursing care in any setting demands for careful adjustment of nurse staffing levels and adequate skill mix to meet patients' nursing care needs. ${ }^{1}$ Nurse staffing reflects the ratio of nurses to patients on a hospital ward. ${ }^{2}$ Information about the amount of time nursing staff spent on various activities is very important for nurse administrators to estimate number of nursing staff required. It also gives them with evidence to maximize productivity by evaluating the appropriateness of staff deployment and skill mix. ${ }^{3}$

Literature review revealed that there is growing concern on

\begin{tabular}{|c|}
\hline Access this article online \\
\hline Quick Response Code \\
\hline
\end{tabular}
nursing shortage and high turnover of nurses. High patient to nurse ratios increases nurses' burnout and job dissatisfaction. Adequate nurse staffing is very important to deliver quality nursing care to patients in clinical setting and to improve patients' satisfaction with nursing care. ${ }^{45,6,7}$ It is utmost importance to understand how much time nurses spend to give direct nursing care in order to assess nursing work load demands. Nursing staff in a ward also participate in other "indirect" patient related activities where there are no hands on contact with the patients such as ward rounds, goal planning and other multi disciplinary team meetings where nursing input is of paramount importance. In addition nursing staff in also have non clinical duties and continued professional development which form part of nursing workload in any ward setting. ${ }^{1}$ therefore, it is necessary to know the proportion of nursing workload assigned to other activities and how nursing activities vary throughout the day and this information is used to estimate the actual staffing requirements.

The most popular and reliable method available is activity analysis which helps to understand proportion of nursing work load, how nursing staff spend their time in medical 
wards in order to estimate nursing man hours per patient and to calculate required number of nursing staff. ${ }^{8}$ In India, very few studies were conducted on activity analysis. Thus, it was decided to conduct activity analysis in a medical ward with an aim to identify the relative proportion of observed workload in different categories of activity such as basic patient care, complex patient care, administration, education, clerical, housekeeping, maintenance, off station and non productive activities and to identify trends of variation in nursing activities throughout the day.

\section{Materials And Methods:}

A work sampling observational study was conducted over a week. This technique was first developed by Tippettin 1935 for use in industrial engineering and management. ${ }^{3}$ The study was conducted in a 39 bedded medical ward. This ward is equipped with central oxygen supply, suction facilities, dressing trolley and emergency equipments. There is a separate room for clinical teaching. The ward also has a laboratory and a treatment room where minor procedures are performed. Patients are admitted through medical OPDs, emergency unit or get transferred from intermediate medical care unit. All registered nurses working in this medical ward and are willing to participate in the study were the participants.

Potential activities of nursing staff were identified from previously published instruments and these activities were grouped into basic patient care, complex patient care, administration, education, clerical, housekeeping, maintenance, off station and non productive. ${ }^{9}$ The face validity of the tool was validated through discussion with the ward supervisor and two senior staff nurses. Content validity was obtained from guide and experts.

Non participatory observation technique was used to record the activities performed by the nursing staff at 10 minutes interval in the observation record for a period of seven days consecutively. After getting formal permission and ethical clearance, study team was formulated with one director and two observers for each shift. Observers were trained for 3 days. Small trail runs of observations were done during that time to solve difficulties encountered and clarify the procedure for collecting data. Study director introduced her and her team members to the nursing staff working in the ward during handover shift meeting and explained about the purpose of the study. This enabled the observer to familiarize with the nursing staff and enabled nursing persons to become comfortable with the observer which could potentially reduce the "Hawthorne effect" and lead to an accurate recording of nursing activities by the observer.

After getting consent from the nursing staffs, observation in a medical ward was conducted at an interval of 10 minutes. The observer recorded all activities being undertaken by every nursing personnel in each round of observation by using observation record. Raw data were analyzed by using descriptive statistics.

\section{Results:}

There were 25 inpatients at the time of study and eight registered nurses were observed for a period of 7 days.

\section{Proportion of observed nursing activities recorded in different categories of activities}

A total of 1335 observation of nursing activities were recorded during this period. Overall complex nursing activities accounted for $66.8 \%$ of the total nursing activities followed by $9.9 \%$ of activities on clerical work, then non productive activities (8.7\%). Only $6.6 \%$ of the activities were basic patient care related and $4.1 \%$ were related with administrative work. Very minimal number of activities was performed on education and no activities related to off station were performed by staff nurses.

\section{Variation in nursing activities at specific time points throughout the day}

As expected, greater proportion of complex nursing activities were observed in the morning shifts. Whilst complex nursing care activities accounted for $66.8 \%$ of the overall nursing activities, these activities declined steadily in the afternoons and were increasingly replaced by clerical activities towards evening. It was also noted that non productive activities $8.7 \%$ of the total activities were observed between $12-2 \mathrm{pm}$. 


\section{Discussion :}

This study was conducted in a medical ward and this may not reflect workload distribution in all medical wards. The study was also confined to a morning, afternoon and evening shifts. There may be differences in activities for nursing staff working in the night shift. Therefore, the pattern identified in the morning and afternoon shifts may not be applicable to the night shift. However, most activities take place in a morning and afternoon shifts and thus the findings are considered relevant to routine nursing care practice in the medical ward. Also only staff nurses were on duty and student nurse did not posted in the ward during the study period.

This study aimed to give a broad overview on proportion of observed work load on different categories of nursing activities. Nurses perform $66.8 \%$ of complex nursing care activities and $9.9 \%$ of clerical activities in medical ward which was supported by the findings of the study revealed that $55.2 \%$ of the activities were complex nursing care activities $11.7 \%$ of clerical activities and only $9.3 \%$ were related to basic care. ${ }^{9}$ Another study results revealed that documentation assessment and administering medication comprised of $70 \%$ of the total activities observed..$^{10}$ It was also supported by another study findings showed that average time spent on medication related activities ranging from $22.8 \%$ in ICU to $29.1 \%$ in combined medical surgical unit. ${ }^{11}$ contradictory results were found in another study revealed that $50 \%$ of nurses time was invested in indirect care intervention and only $22 \%$ on direct care intervention. ${ }^{12}$

\section{Percentage distribution of Activities of the Staff nurse}

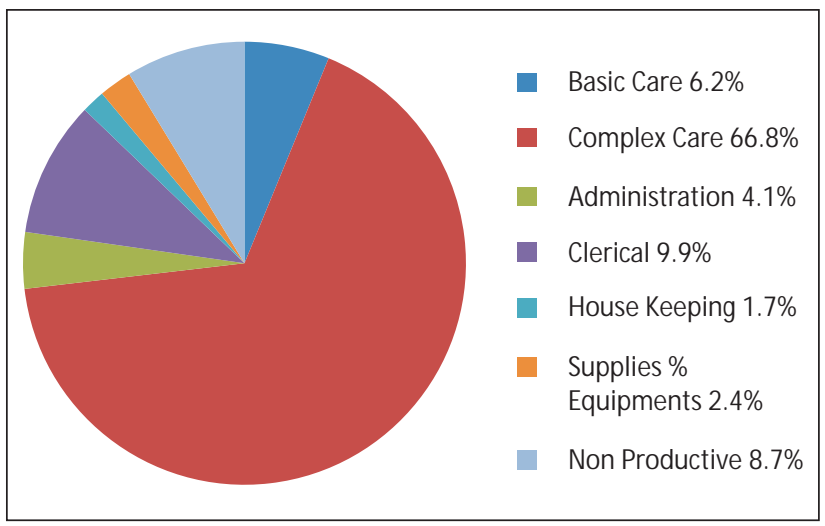

This study gave better understanding about the variations in the nursing workload in morning and afternoon shift. The high percentage $(66.8 \%)$ of complex nursing care activities in the morning supports the findings of work sampling study conducted in surgical ward and the results revealed that staff nurses perform heaviest number of complex care activities in the morning but they continued throughout the day and decreasing at the time of lunch break. ${ }^{9}$ Another study conducted in neuro rehabilitation unit supports the findings and results revealed that $51 \%$ of direct care activities were recorded during early session and $37 \%$ of direct care activities were observed in the late session of the day. ${ }^{1}$

\section{Conclusion:}

This study gives valuable insight into the nursing activities performed by nursing staff in a medical ward throughout the day. The proportion of observed complex care activities were shown to fluctuate throughout the day. Also other activities such as clerical, administrative and non productive activities performed by nurses need to be included while estimating nursing staff requirements of a medical ward.

\section{Percentage Distribution of the Activities of Staff Nurse at specific time points during the week of the Study}

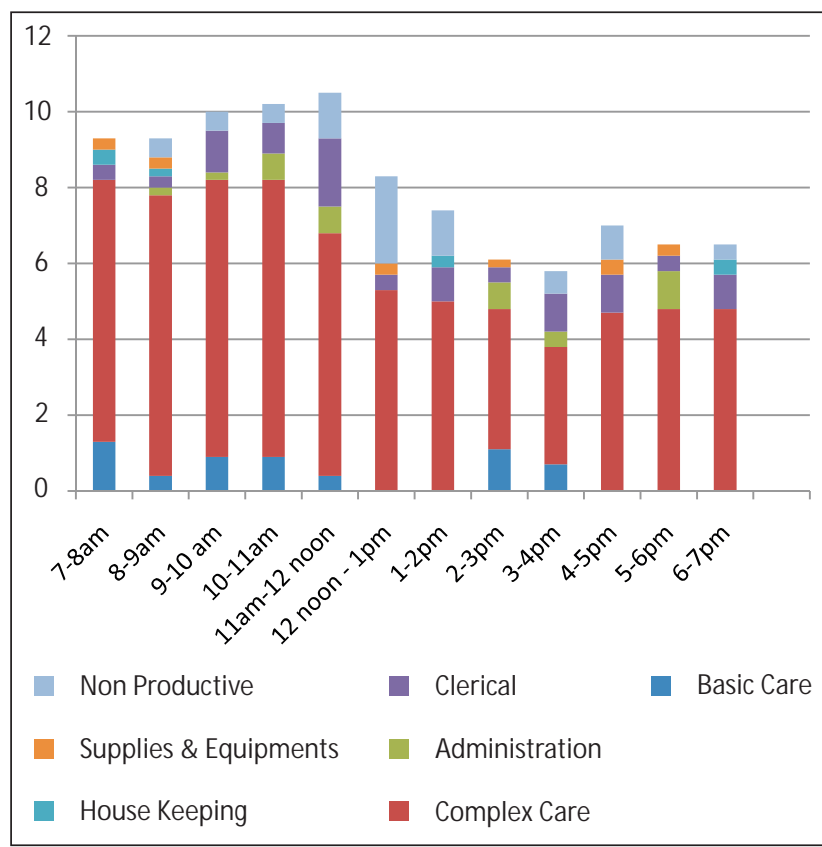




\section{Number and Percentage Distribution of Activities performed} by staff nurses in a medical ward

\begin{tabular}{|cl|c|c|}
\hline S.No Type of Activity & $\begin{array}{c}\text { Number of } \\
\text { Activities }\end{array}$ & $\begin{array}{c}\text { Percentage of } \\
\text { Activities }\end{array}$ \\
\hline 1 & Basic Patient Care & 83 & 6.2 \\
2 & Complex Patient Care & 892 & 66.8 \\
3 & Administration & 56 & 4.1 \\
4 & Education & 1 & $*$ \\
5 & Clerical & 132 & 9.9 \\
6 & Housekeeping & 23 & 1.7 \\
7 & Maintaining Supplies & 32 & 2.4 \\
& and Equipments & 116 & 8.7 \\
8 & Non Productive & 1335 & $\mathbf{1 0 0}$ \\
\hline \multicolumn{2}{|l|}{ Total } & & \\
\hline
\end{tabular}

Note : ${ }^{*}$ indicates $<.5 \%$

\section{References:}

1. Williams H., Harris R and Turner- Stokes L. Work sampling : a quantitative analysis of nursing activity in a neuro - rehabilitation setting. Journal of Advances Nursing $2009 \mathrm{M}$ ay; 65(10):2097-2107.

2. Nurse staffing. Retrived on 15.02.2013 http://www.ehow.com / facts_6947788-definition_nurse_staffing.html.

3. M unyisia EN, Yu P and Hailey D. How nursing staff spend their time on activities in a nursing home: an observational study. Journal of Advanced Nursing 2011 Jan; 00 (1):01-10.

4. Cho SH.etal. Nurse staffing, quality of nursing care and nurse job outcomes in intensive care units, Journal of Clinical Nursing 2009 Jun; 18(12):1729-37.

5. Aiken LH, Clarke SP, Sloane DM, Sochalski J and Silber JH. Hospital Nurse Staffing and Patient mortality, nurse burnout, and job dissatisfaction, Journal of American Medical Association 2002 Oct; 288(16): 1987-1993.

6. Doran $D$ and . Nurse staffing models, nursing hours, and patient safety outcomes. The Journal of Nursing Administration 2004 Jan;34(1):41-5.

7. Liang YW, Chen WY, Lee JL and Huang LC. Nurse staffing, direct nursing care hours and patient mortality in Taiwan: the longitudinal analysis of hospital nurse staffing and patient outcome study. BMC Health Services Research 2012 Feb 20;12:44.

8. Williams S, Whelan A, Weindling AM and Cooke RWI. Archives of Disease in Childhood 1993; 68: 534-538.

9. Darbyshire BM. Guide to the Study of Activities of Health personnel in Hospital, 1969; July. WHO Regional Office for South East Asia, New Delhi.

10. Keohane CA. et.al. Quantifying Nursing Workflow in medication Administration. The Journal of Nursing Administration 2008 Jan; 38(1):19-26.

11. Bordin LC and Fugulin FM . Nurses' time distribution : dentification and analysis in a medical surgical unit. Retrived on 15.02.2013. http://www.ncbi.nlm.nih.gov/pubmed/20085153

12. Battisto D, Pak R, Wood MAV and Pilcher JJ. Using a Task analysis to describe Nursing work in Acute care patient Environments. The Journal of Nursing administration 2009 Dec;39(12):537-547.

\section{Acknowledgments:}

We thank the management, staff and final year nursing students of the analyzed hospital for their cooperation and support. 